\title{
Training Effect on Microstructure and Shape Recovery in Ti-Pd-Zr Alloys
}

\author{
Hirotaka Sato $^{1,2}$, Hee Young Kim ${ }^{3}$, Masayuki Shimojo ${ }^{1}$ and Yoko Yamabe-Mitarai ${ }^{2, *}$ \\ ${ }^{1}$ Shibaura Institute of Technology, Tokyo 135-8548, Japan \\ ${ }^{2}$ National Institute for Materials Science, Tsukuba 305-0047, Japan \\ ${ }^{3}$ University of Tsukuba, Tsukuba 305-8577, Japan
}

\begin{abstract}
The training effect of microstructure and shape recovery on Ti-50Pd-xZr $(\mathrm{x}=7$ and 10$)$ at $\%$ and $\mathrm{Ti}-50 \mathrm{Pd}-\mathrm{xZr}-(5-\mathrm{x}) \mathrm{V}(\mathrm{x}=1,2.5$, and 4$)$ high-temperature shape memory alloys were investigated. $\mathrm{Zr}$ was selected as an alloying element as it is known to improve the shape recovery of TiPd. As a further alloying element, $\mathrm{V}$ was selected because it is effective in strengthening TiPd. The dependence of $\mathrm{Zr}$ content and $\mathrm{V}$ addition on the martensitic transformation (MT) temperature, shape recovery, and training effect were investigated. For example, $M_{\mathrm{f}}$, decreased with increasing $\mathrm{Zr}$ from $480^{\circ} \mathrm{C}$ in $\mathrm{Ti}-50 \mathrm{Pd}$ to $302^{\circ} \mathrm{C}$ in Ti-50Pd-10Zr. In Ti-50Pd-xZr- $\left.5-\mathrm{x}\right) \mathrm{V}$, when the total amount of $\mathrm{Zr}$ and $\mathrm{V}$ was 5 at $\%$, the MT temperatures did not change drastically. The MT temperatures ranged between 350 and $550^{\circ} \mathrm{C}$.

Shape recovery was investigated using the thermal cyclic test under a constant applied stress in the range of 15 to $200 \mathrm{MPa}$. Perfect recovery was obtained at low stresses, while irrecoverable strain was observed at high stresses. For Ti-50Pd-2.5Zr-2.5V and Ti-50Pd-1Zr-4V, creep deformation was observed above $150 \mathrm{MPa}$. To obtain perfect recovery, training (repeated thermal cyclic tests under a constant applied stress) was performed. Perfect recovery was obtained for the alloys by training, except for Ti-50Pd-4Zr-1V. Ti-50Pd-10Zr achieved perfect recovery up to $200 \mathrm{MPa}$, while Ti-50Pd-1Zr-4V achieved perfect recovery up to $150 \mathrm{MPa}$. Other alloys achieved perfect recovery at lower stresses of 65 or $50 \mathrm{MPa}$. The microstructure changed from a random martensite variant to a specific orientation during training, to accommodate the large strain during deformation. It was found that a strong texture led to perfect shape recovery. [doi:10.2320/matertrans.MAW201706]
\end{abstract}

(Received May 15, 2017; Accepted July 5, 2017; Published August 4, 2017)

Keywords: TiPd, thermomechanical test, shape recovery, high-temperature shape memory alloys, B2, B19

\section{Introduction}

Shape memory alloys (SMAs) can recover the strain introduced in the martensite phase to return to the pre-deformed shape when they are heated above the austenite finish temperature $\left(A_{\mathrm{f}}\right)$ due to reverse martensitic transformations (MTs). That is, temperatures that can recover their shape depend on the martensitic transformation temperature. Commercially available SMAs are mainly NiTi, which can be used for a variety of applications such as actuators, home electric appliances, and medical devices ${ }^{1)}$. Martensitic transformation in NiTi occurs between the B2 structure in austenite and the B19' monoclinic structure in martensite. However, they are not suitable for use at temperatures above $100^{\circ} \mathrm{C}$ because their martensitic transformation temperature is below $100^{\circ} \mathrm{C}$. On the other hand, high-temperature shape memory alloys (HTSMAs) are attracting much interest for their ability to operate above $200^{\circ} \mathrm{C}$, enabling their use in various devices in aerospace and automotive applications ${ }^{2}$.

Therefore, enormous efforts have been made to develop HTSMAs. To raise the martensitic transformation temperature, NiTi has been alloyed with $\mathrm{Au}, \mathrm{Pd}, \mathrm{Pt}, \mathrm{Hf}$, and $\mathrm{Zr}^{2}$. The first development in this regard was the study of NiTi-Pt or NiTi-Pd alloys whose MT temperatures are above $200^{\circ} \mathrm{C}^{3-8)}$. However, in recent years, the trend shifted to $\mathrm{Ni}$ $\mathrm{Ti}-\mathrm{Zr}$ and NiTi-Hf alloys whose MT temperatures are between 100 and $200^{\circ} \mathrm{C}$, rendering them suitable for automotive applications rather than aerospace applications ${ }^{9-21)}$.

TiPd is also considered a HTSMA due to a high MT temperature of around $570^{\circ} \mathrm{C}$. Martensitic transformation of TiPd occurs between the B2 structure in austenite and the

*Corresponding author, E-mail: mitarai.yoko@nims.go.jp
B19 orthorhombic structure in martensite. The shape memory effect in a $\mathrm{Ti}_{50} \mathrm{Pd}_{50}$ alloy was first discovered in $1993^{22)}$; however, in this alloy, the shape recovery drastically decreased with increasing temperature due to plastic deformation at high temperature. Ni addition to TiPd was next investigated $^{23-25)}$; however, a simple $\mathrm{Ni}$ addition could not achieve perfect shape recovery.

In our previous study, we focused on the addition of different alloying elements into TiPd to improve its strength, of which $\mathrm{Zr}$ was found to be the most promising alloying element $^{26-28)}$. For example, the addition of 5 at $\% \mathrm{Zr}$ to TiPd improved the shape recovery ratio from $13 \%$ in the TiPd binary alloy to $94 \%$ after being tested at $380^{\circ} \mathrm{C}^{28}$. It was found that $5 \% \mathrm{Zr}$ addition effectively improved the shape recovery. Therefore, this study investigates the effect of further $\mathrm{Zr}$ addition on shape recovery. A previous study also indicated that $\mathrm{V}$ addition drastically improved the strength of both the martensite and austenite phases ${ }^{26)}$. Hence, the effect of $\mathrm{V}$ addition on the shape recovery of Ti-Pd-Zr was also investigated. Another attempt to improve the shape recovery is the training of SMAs; that is, thermomechanical cycling ${ }^{29)}$. Therefore, in this study, the training effect on microstructure and shape recovery was investigated for $\mathrm{TiPd}-\mathrm{Zr}$ and $\mathrm{TiPd}-$ $\mathrm{Zr}-\mathrm{V}$ alloys.

\section{Experimental Procedure}

$15 \mathrm{~g}$ ingots with a nominal composition of Ti-50Pd-7Zr, Ti-50Pd-10Zr, Ti-50Pd-4Zr-1V, Ti-50Pd-2.5Zr-2.5V, and Ti$50 \mathrm{Pd}-1 \mathrm{Zr}-4 \mathrm{~V}$ (at\%) were melted by the arc melting method. They were encapsulated in a quartz tube with $\mathrm{Ar}$ gas and heated at $1000^{\circ} \mathrm{C}$ for $3 \mathrm{~h}$, and then quenched in iced water. After the heat treatment, the ingots were loaded into the testing machine and compressed at $1000^{\circ} \mathrm{C}$ in air atmosphere to 
$40 \%$ of the initial thickness to form disk-like samples.

A plate of $0.8 \mathrm{~mm}$ thickness was cut from the ingot parallel to the compressed direction for X-ray diffraction measurements (XRD) (Rigaku Co., Ltd., RINT TTR-III), which were performed to identify the crystal structure using $\mathrm{Cu} \mathrm{K}_{\alpha}$ radiation at $50 \mathrm{kV}$ and $300 \mathrm{~mA}$.

A scanning electron microscope (SEM) (JEOL Ltd, JEOL 7001F) was used at an accelerating voltage of $20 \mathrm{kV}$ to observe the microstructure parallel to the compressed direction. The MT temperature of all the alloys was measured by differential scanning calorimetry (DSC) (TA Instruments Japan Inc., DSC Q10) performed with a scanning rate of $10^{\circ} \mathrm{C} / \mathrm{min}$ for samples. The weight of each DSC sample was about $150 \mathrm{mg}$.

To investigate the alloys' strength, a compression test was carried out on samples $2.5 \times 2.5 \times 5 \mathrm{~mm}$ in size with an initial strain rate of $3 \times 10^{-4} / \mathrm{s}$ at $30^{\circ} \mathrm{C}$ below the martensite finish temperature $\left(M_{\mathrm{f}}\right)$ and at $30^{\circ} \mathrm{C}$ above the austenite finish temperature $\left(A_{\mathrm{f}}\right)$ (Shimadzu Corp., AG-X test system), respectively. A mechanical test of the mertensite phase indicated double yielding behavior. In martensite phase, the first yielding stress indicates martensite detwining stress and the second yielding stress indicates yielding by plastic deformation. Then, $0.2 \%$ proof stress of the martensite phase was obtained from the second yield stress. For the austenite phase, samples isothermally deformed to $1 \%$ and unloaded in loading-unloading test and the applied strain was increased for each loading-unlading cycle. $0.2 \%$ proof stress of the austenite phase was obtained from the stress-strain curve by plotting plastic strain and maximum stress for each loading-unloading cycle. To investigate the shape recovery and work output, thermal cyclic test was performed in the temperature range of $M_{\mathrm{f}}-30^{\circ} \mathrm{C}$ to $A_{\mathrm{f}}+30^{\circ} \mathrm{C}$ under compressive stresses. In the thermal cyclic test, the sample was first heated to $A_{\mathrm{f}}+30^{\circ} \mathrm{C}$, then cooled to $M_{\mathrm{f}}-30^{\circ} \mathrm{C}$, and again heated to $A_{\mathrm{f}}+30^{\circ} \mathrm{C}$. The transformation and irrecoverable strains of the samples were measured by direct observation of the sample shape using the CCD camera in the compression testing machine. We calculated the shape recovery and work output using the following equations from the strain-temperature curve.
Shape recovery ratio $(\%)=$ Recovery strain/Transformation strain

Work output $\left(\mathrm{J} / \mathrm{cm}^{3}\right)=$ Recovery strain $\times$ Applied stress (MPa)

To improve the shape recovery, training was also applied to all the alloys. Training is the process of repeated thermal cyclic testing under constant stress. We investigated the maximum applied stress and the necessary cycles required to achieve full recovery. The maximum stress was identified by the following method: The thermal cycle test was performed several times under an arbitrary stress that caused irrecoverable strain. The applied stress was then decreased until the irrecoverable strain disappeared. The stress that did not cause irrecoverable strain was defined as the maximum stress required for perfect shape recovery.

\section{Results}

\subsection{Microstructures}

After $40 \%$ deformation at $1273 \mathrm{~K}$, the samples were observed by SEM. A twin structure, which forms during martensitic transformation, was found in all the tested samples, as shown in Fig. 1, thus confirming the occurrence of martensitic transformation. Ti-Pd-Zr had precipitates along the grain boundaries, which were identified as $\mathrm{Ti}_{2} \mathrm{Pd}^{28)}$. However, the $\mathrm{Ti}_{2} \mathrm{Pd}$ precipitates were not clearly formed in $\mathrm{Ti}-$ 50Pd-2.5Zr-2.5V and Ti-50Pd-1Zr-4V.

\subsection{Transformation temperature}

Table 1 and Fig. 2 show the result of transformation temperature measured by DSC. For reference, the transformation temperature of Ti-50Pd binary alloy ${ }^{28,30)}$ and Ti-50Pd$5 \mathrm{Zr}^{28,30)}$ and $\mathrm{Ti}-50 \mathrm{Pd}-5 \mathrm{~V}^{30)}$ ternary alloys are also indicated. In Fig. 2 (a), the dependence of transformation temperature on the $\mathrm{Zr}$ content is shown for Ti-50Pd-Zr, together with the results for $\mathrm{Ti}-50 \mathrm{Pd}^{28,30)}$ and $\mathrm{Ti}-50 \mathrm{Pd}-5 \mathrm{Zr}^{28,30)}$. The transformation temperature decreased with increasing $\mathrm{Zr}$ content and dropped to $302^{\circ} \mathrm{C}$ for $M_{\mathrm{f}}$ and $416^{\circ} \mathrm{C}$ for $A_{\mathrm{f}}$ for TiPd10Zr. On the other hand, the temperature hysteresis increased with increasing $\mathrm{Zr}$ content. Figure 2 (b) shows the transformation temperature of Ti-Pd-Zr-V. For reference, the

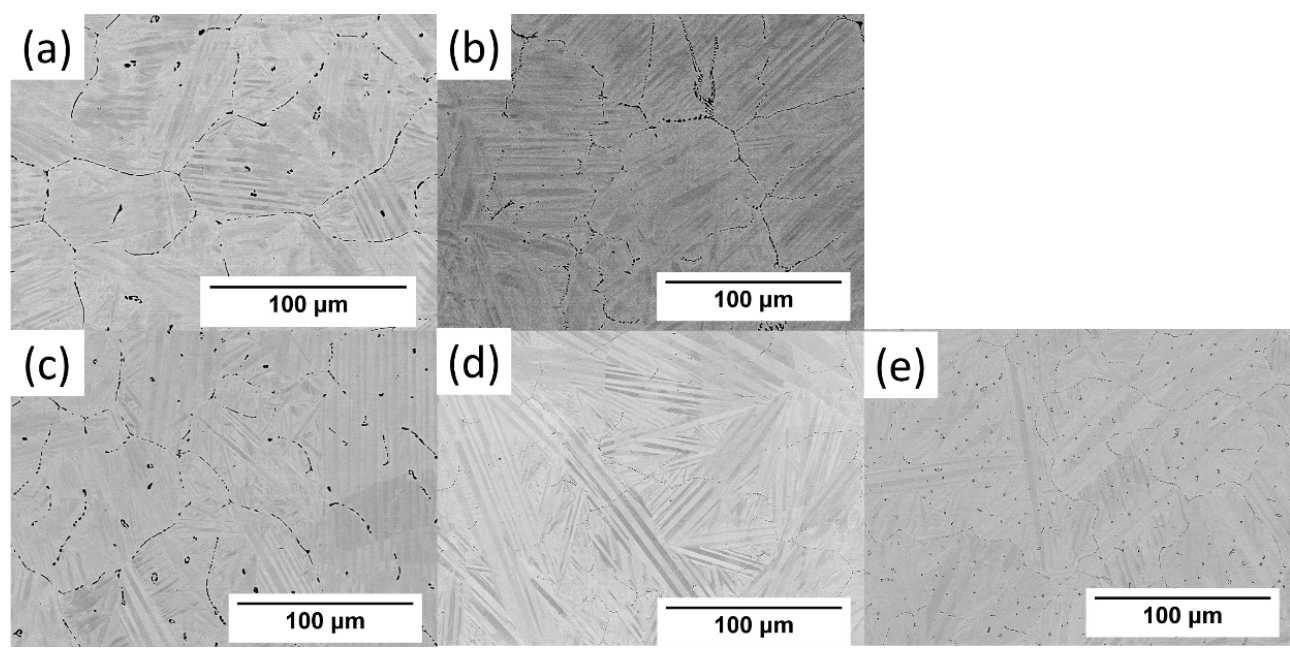

Fig. 1 Back-scattered images of (a) Ti-50Pd-7Zr, (b) Ti-50Pd-10Zr, (c) Ti-50Pd-4Zr-1V, (d) Ti-50Pd-2.5Zr-2.5V, and (e) Ti-50Pd-1Zr-4V. 
transformation temperature of $\mathrm{Ti}-50 \mathrm{Pd}-5 \mathrm{Zr}^{28,30)}$ and $\mathrm{Ti}$ $50 \mathrm{Pd}-5 \mathrm{~V}^{30)}$ are also plotted. While $A_{\mathrm{s}}$ and $A_{\mathrm{f}}$ increased with increasing $\mathrm{Zr}$ content of up to $2.5 \%, M_{\mathrm{s}}$ and $M_{\mathrm{f}}$ dropped with increasing $\mathrm{Zr}$ content, resulting in the increase in thermal hysteresis. When the amount of $\mathrm{V}$ was above $2.5 \mathrm{at} \%, A_{\mathrm{s}}$ and $A_{\mathrm{f}}$ decreased while $M_{\mathrm{s}}$ and $M_{\mathrm{f}}$ increased, resulting in a decrease in the thermal hysteresis.

\subsection{Mechanical property of alloys}

Table 2 summarizes $0.2 \%$ proof stress of the TiPd alloys at $M_{\mathrm{f}}-30^{\circ} \mathrm{C}$ and $A_{\mathrm{f}}+30^{\circ} \mathrm{C}$ measured by the compression test. The result in Table 2 is plotted as a function of test temperature in Fig. 3. The strengths of martensite and austenite in Ti-50Pd-10Zr were higher than that of the other alloys due to its low transformation temperature. On the other hand, the strength of the martensite phase in Ti-50Pd-1Zr$4 \mathrm{~V}$ is the same as that of the martensite phase in Ti-50Pd10Zr. Despite similar transformation temperatures among Ti-Pd-Zr-V alloys, only Ti-50Pd-1Zr-4V have higher martensite and austenite strengths. This indicates the high solution hardening effect of $\mathrm{V}$. The strengths of martensite in Ti50Pd-7Zr, Ti-50Pd-4Zr-1V, and Ti-50Pd-2.5Zr-2.5V are similar due to the close $M_{\mathrm{f}}$ temperatures. However, the strengths of their austenite phases decreased with increase in $A_{\mathrm{f}}$ temperature.

\subsection{Shape memory effect}

The thermal cyclic test was carried out under the stresses of $15 \mathrm{MPa}, 50 \mathrm{MPa}, 100 \mathrm{MPa}, 150 \mathrm{MPa}$, and $200 \mathrm{MPa}$, to

Table 1 Martensitic transformation temperature $\left({ }^{\circ} \mathrm{C}\right)$ of Ti-50Pd alloys.

\begin{tabular}{|c|c|c|c|c|}
\hline Alloys & $M_{\mathrm{f}}$ & $M_{\mathrm{S}}$ & $A_{\mathrm{s}}$ & $A_{\mathrm{f}}$ \\
\hline $\mathrm{Ti}-50 \mathrm{Pd}^{28,30)}$ & 480 & 510 & 520 & 550 \\
\hline Ti-50Pd-5Zr $\mathrm{Zr}^{28,30)}$ & 445 & 467 & 493 & 509 \\
\hline Ti-50Pd-7Zr & 400 & 421 & 451 & 469 \\
\hline Ti-50Pd-10Zr & 302 & 322 & 348 & 416 \\
\hline Ti-50Pd-4Zr-1V & 384 & 409 & 497 & 508 \\
\hline Ti-50Pd-2.5Zr-2.5V & 368 & 393 & 523 & 546 \\
\hline Ti-50Pd-1Zr-4V & 424 & 441 & 496 & 518 \\
\hline Ti-50Pd-5V & 443 & 461 & 525 & 562 \\
\hline
\end{tabular}

(a)

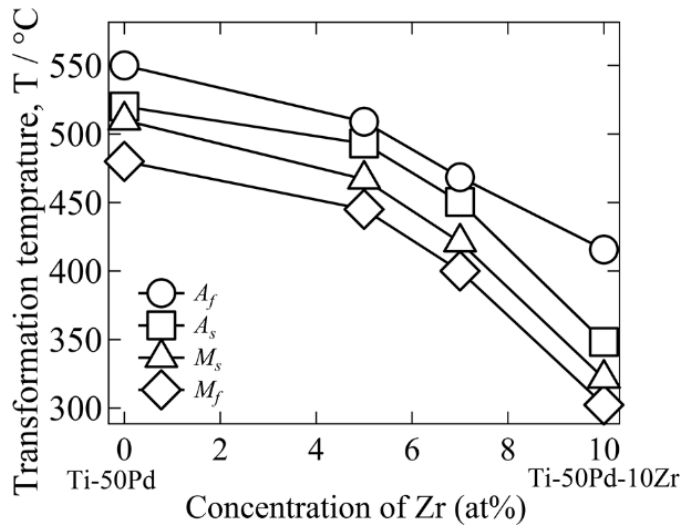

investigate the shape memory effect. Figure 4 shows the results of the tests under each condition, except for the result of Ti-50Pd-1Zr-4V under $15 \mathrm{MPa}$ since that measurement did not succeed. As seen in Fig. 4, the transformation strain $\left(\varepsilon_{\mathrm{r}}\right)$ increased with increasing applied stress; however, irrecoverable strain appeared at increased applied stress. The strain-temperature curves of Ti-50Pd-2.5Zr-2.5V and Ti$50 \mathrm{Pd}-1 \mathrm{Zr}-4 \mathrm{~V}$ represent a trumpet-like shape when the applied stress is above $150 \mathrm{MPa}$. The trumpet-like strain-temperature curves indicate that the thermal expansion is smaller than the deformation during the rising temperature. If the applied stress is smaller than $0.2 \%$ proof stress at $A_{\mathrm{f}}+$ $30^{\circ} \mathrm{C}$, then the deformation is considered to proceed as

Table $20.2 \%$ proof stress $(\mathrm{MPa})$ of Ti-50Pd alloys at $M_{\mathrm{f}}-30$ and $A_{\mathrm{f}}+30$ $\left({ }^{\circ} \mathrm{C}\right)$.

\begin{tabular}{lcc}
\hline Alloys & $M_{\mathrm{f}}-30$ & $A_{\mathrm{f}}+30$ \\
\hline Ti-50Pd-7Zr & 930 & 355 \\
Ti-50Pd-10Zr & 1267 & 547 \\
Ti-50Pd-4Zr-1V & 871 & 232 \\
Ti-50Pd-2.5Zr-2.5V & 916 & 186 \\
Ti-50Pd-1Zr-4V & 1268 & 372 \\
\hline
\end{tabular}

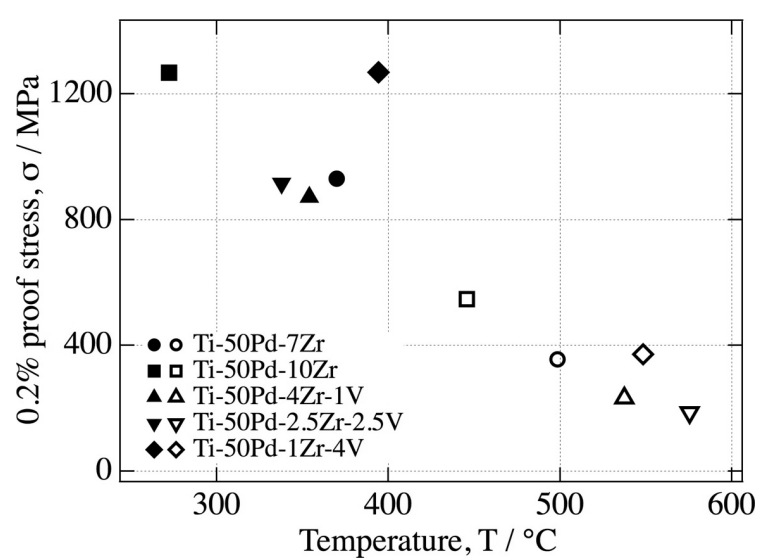

Fig. $30.2 \%$ Proof stress of Ti-50Pd-Zr and Ti-50Pd-Zr-V alloys at $M_{\mathrm{f}}-30$ and $A_{\mathrm{f}}+30^{\circ} \mathrm{C}$.

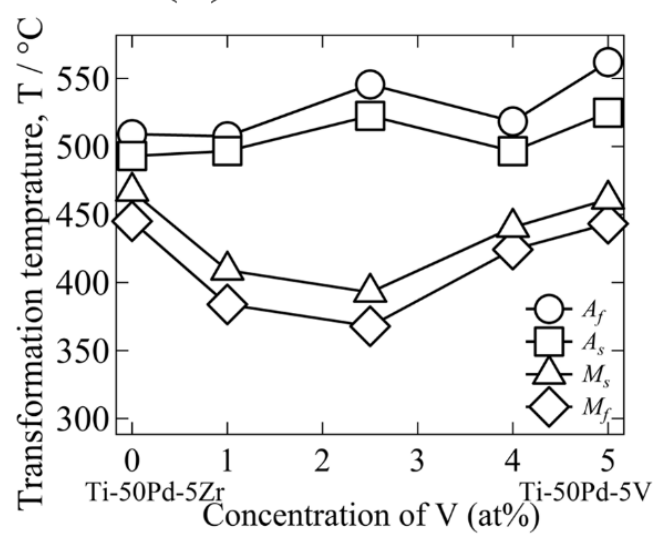

Fig. 2 Martensitic transformation temperature of (a) Ti-50Pd-Zr and (b) Ti-50Pd-Zr-V alloys 
creep. Creep deformation suggests that these shape memory alloys cannot be used at applied stresses above $150 \mathrm{MPa}$. The shape recovery and work output were estimated from the strain-temperature curves in Fig. 4 and those plotted as a function of applied stress in Fig. 5. The work output increased with increasing applied stress for all the alloys (Fig. 5(a)), and decreased with increasing $\mathrm{Zr}$ and $\mathrm{V}$ contents. Since work output is estimated as a product of applied stress and recovery strain, the order of work output represents the magnitude of recovery strain at the same applied stress. Shape recovery, which is the ratio of recovery strain and transformation strain of the Ti-Pd-Zr alloys, was above $90 \%$ for up to $150 \mathrm{MPa}$. The shape recovery of Ti-50Pd-7Zr was smaller than that of Ti-50Pd-10Zr. Although a perfect recovery was achieved at $15 \mathrm{MPa}$ in Ti-50Pd-Zr-V, shape recovery decreased more drastically with an increase in $\mathrm{V}$ as compared to that in Ti-Pd-Zr.

\subsection{Training effect}

Thermomechanical treatment (training) was performed using the conditions presented in Table 3. All the alloys were trained by the repeated thermal cyclic tests under the stress chosen from Fig. 4 that generated a small irrecoverable strain. When the irrecoverable strain became steady after the repeated cycles, we lowered the stress stepwise until the irrecoverable strain disappeared.

For example, Ti-50Pd-7Zr was trained for 1 cycle under a stress of $200 \mathrm{MPa}$, during which the irrecoverable strain did not disappear. The stress was thus reduced to $150 \mathrm{MPa}$. A

Table 3 Training condition. Number of cycles for each applied stress (MPa).

\begin{tabular}{lccccccc}
\hline alloys & 200 & 150 & 100 & 75 & 70 & 65 & 50 \\
\hline Ti-50Pd-7Zr & 1 & 4 & 43 & 0 & 0 & 0 & 18 \\
Ti-50Pd-10Zr & 31 & 0 & 0 & 0 & 0 & 0 & 0 \\
Ti-50Pd-4Zr-1V & 0 & 0 & 0 & 0 & 0 & 0 & 76 \\
Ti-50Pd-2.5Zr-2.5V & 0 & 0 & 18 & 19 & 19 & 1 & 0 \\
Ti-50Pd-1Zr-4V & 32 & 6 & 0 & 0 & 0 & 0 & 0 \\
\hline
\end{tabular}

(a)

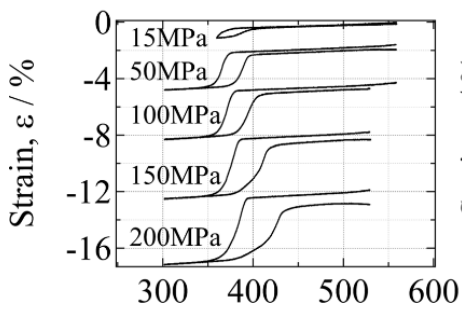

(c) Temperature, $\mathrm{T} /{ }^{\circ} \mathrm{C}$

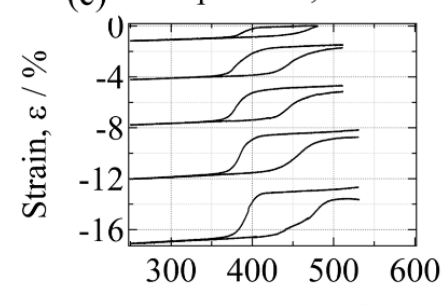

Temperature, $\mathrm{T} /{ }^{\circ} \mathrm{C}$ (b)

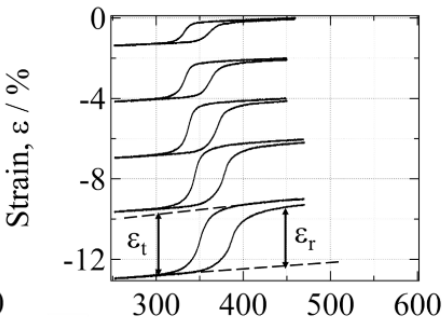

(d)

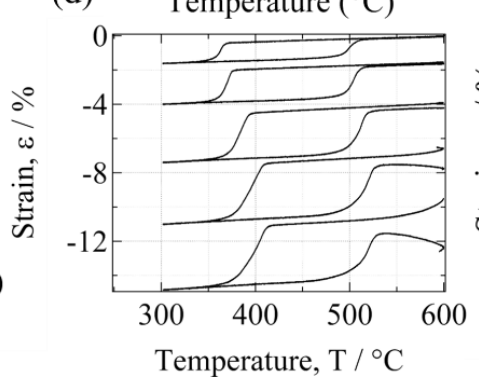

(e)

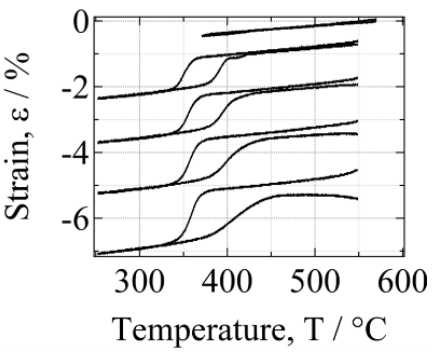

Fig. 4 Strain-Temperature curves of (a) Ti-50Pd-7Zr, (b) Ti-50Pd-10Zr, (c) Ti-50Pd-4Zr-1V, (d) Ti-50Pd-2.5Zr-2.5V, and (e) Ti-50Pd-1Zr-4V. From top to bottom, the applied stress is $15,50,100,150$, and $200 \mathrm{MPa}$, where $\varepsilon_{\mathrm{t}}$ is the transformation $\operatorname{strain}(\%)$ and $\varepsilon_{\mathrm{r}}$ is the recoverable strain $(\%)$.

(a)

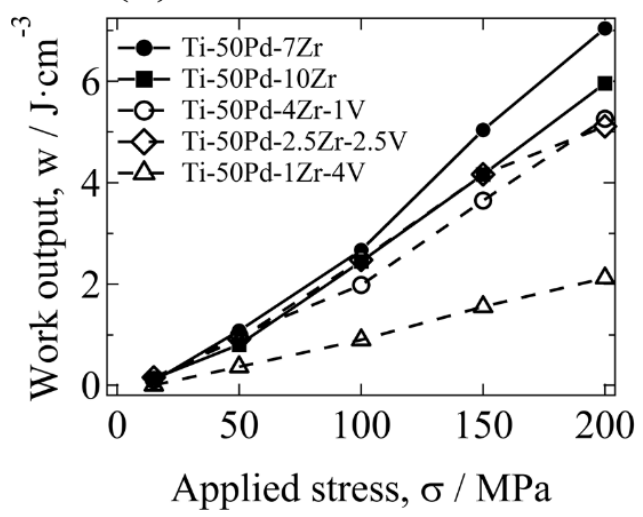

(b)

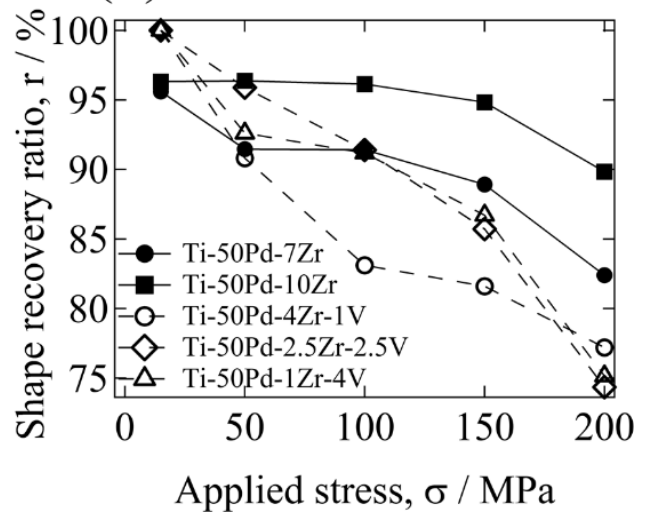

Fig. 5 (a) Work output and (b) shape recovery of Ti-50Pd alloys. 
large irrecoverable strain was found under $150 \mathrm{MPa}$, following which the stress was further reduced to $100 \mathrm{MPa}$. Since large deformation was not observed under $100 \mathrm{MPa}$, this stress value was used as an appropriate training condition under which 43 cycles of the thermal cyclic test was performed. However, the irrecoverable strain was still remained after training for 43 cycles. Thus, the applied stress was again reduced to $50 \mathrm{MPa}$. Perfect recovery could be achieved by training at $50 \mathrm{MPa}$, and the obtained strain-temperature curve is shown in Fig. 6(a).

Ti-50Pd-10Zr perfectly recovered by the training of 31 cycles under a constant stress of $200 \mathrm{MPa}$. The strain-temperature curve obtained after perfect shape recovery is shown in Fig. 6(b). Ti-50Pd-10Zr recovered under the greatest stress among all the tested alloys.

Ti-50Pd-4Zr-1V could not perfectly recover even after 76 cycles under $50 \mathrm{MPa}$. The strain-temperature curve is shown in Fig. 6 (c).

Ti-50Pd-2.5Zr-2.5V exhibited a large thermal hysteresis, as shown in Fig. 2. However, as training continued, $A_{\mathrm{s}}$ and $A_{\mathrm{f}}$ decreased to lower temperatures, and the thermal hysteresis decreased as well. Perfect shape recovery was obtained for 1 cycle at $65 \mathrm{MPa}$ after 18 cycles at $100 \mathrm{MPa}, 19$ cycles at $75 \mathrm{MPa}$, and 19 cycles at $70 \mathrm{MPa}$. The strain-temperature curve for perfect recovery is shown in Fig. 6 (d).

The training of Ti-50Pd-1Zr-4V was started from $200 \mathrm{MPa}$. After 8 cycles, the irrecoverable strain was stabilized at $0.002 \%$. Since the irrecoverable strain did not decrease even after 32 cycles at $200 \mathrm{MPa}$, the training stress was lowered to $150 \mathrm{MPa}$ for 6 cycles. Then, the irrecoverable strain disappeared. The strain-temperature curve for perfect recovery is shown in Fig. 6 (e).

Except for Ti-50Pd-4Zr-1V, the alloys possessed the ability to fully recover under the stress of $50 \mathrm{MPa}$ or more. The training stress required to obtain perfect shape recovery depended on the alloy composition. Among the tested alloys, Ti-50Pd-10Zr and Ti-50Pd-1Zr-4V recovered under relatively large stresses of $200 \mathrm{MPa}$ and $150 \mathrm{MPa}$, respectively. The perfect recovery strain decreased with increasing $\mathrm{Zr}$ and $\mathrm{V}$ contents in the ternary and quaternary alloys, respectively. The recovered strain was smaller in the quaternary alloys as compared with that of the ternary alloys, indicating a decrease in the transformation strain due to the addition of $\mathrm{V}$.

\subsection{Change of texture by training}

Inverse pole figure maps before and after training under the conditions shown in Table 3, are shown in Figs. 7 and 8, respectively. The observed plane is normal to the compressive direction. Before the training, as shown in Fig. 7, the crystal orientation of each alloy was relatively random. After training, the crystal orientation started to align in one direction, as shown in Fig. 8.

\section{Discussion}

\subsection{Effect of $\mathrm{Zr}$ and $\mathrm{V}$}

Considering that the shape memory alloys work around the transformation temperature, the strength around the phase transformation temperature is considered to affect the shape recovery behavior. Thus, the strength at $A_{\mathrm{f}}+30$ and $M_{\mathrm{f}}-30^{\circ} \mathrm{C}$ were investigated. As shown in Table 2 and Fig. 3, in the Ti-50Pd-Zr ternary alloys, the strength of the martensite and austenite phases increased with increasing $\mathrm{Zr}$ content. This is because the transformation temperature decreased with increasing $\mathrm{Zr}$ content. The higher shape recovery of Ti-50Pd-10Zr than that of Ti-50Pd-7Zr causes high strength of Ti-50Pd-10Zr as shown in Fig. 5(b). However, the addition of $\mathrm{Zr}$ decreased transformation strain resulting in smaller work output as shown in Fig. 5 (a).

When $\mathrm{Zr}$ and $\mathrm{V}$ were added together, despite their transformation temperatures being similar, the strengths of martensite and austenite in $\mathrm{Ti}-50 \mathrm{Pd}-1 \mathrm{Zr}-4 \mathrm{~V}$ were higher than those of the other two alloys, as shown in Fig. 3. This indicates that 4 at $\% \mathrm{~V}$ addition is very effective in improving the strengths of the martensite and austenite phase. However, as shown in Fig. 5 (b), the shape recovery ratios of Ti-50Pd-

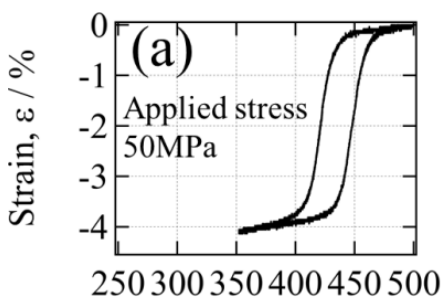

Temperature, $\mathrm{T} /{ }^{\circ} \mathrm{C}$

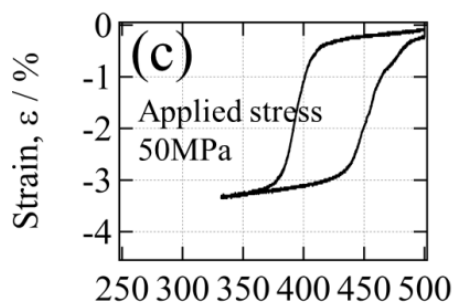

Temperature, $\mathrm{T} /{ }^{\circ} \mathrm{C}$

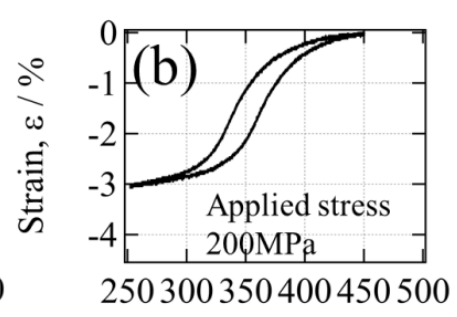

Temperature, $\mathrm{T} /{ }^{\circ} \mathrm{C}$

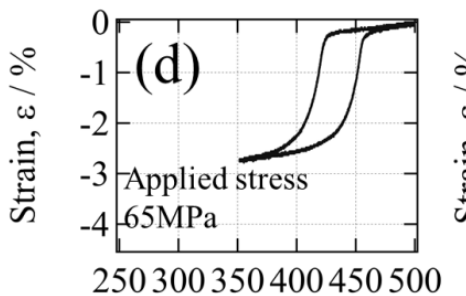

Temperature, $\mathrm{T} /{ }^{\circ} \mathrm{C}$

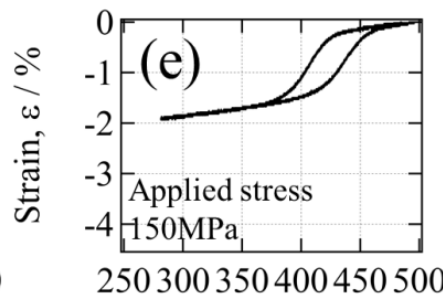

Temperature, $\mathrm{T} /{ }^{\circ} \mathrm{C}$

Fig. 6 Strain-temperature curves of (a) Ti-50Pd-7Zr after 18 cycles at $50 \mathrm{MPa}$, (b) Ti-50Pd-10Zr after 31 cycles at $200 \mathrm{MPa}$, (c) To-50Pd-4Zr-1V after 76 cycles at $50 \mathrm{MPa}$, (d) Ti-50Pd-2.5Zr-2.5V after 1 cycle at $65 \mathrm{MPa}$, and (e) Ti-50Pd-1Zr-4V after 6 cycles at $150 \mathrm{MPa}$ 

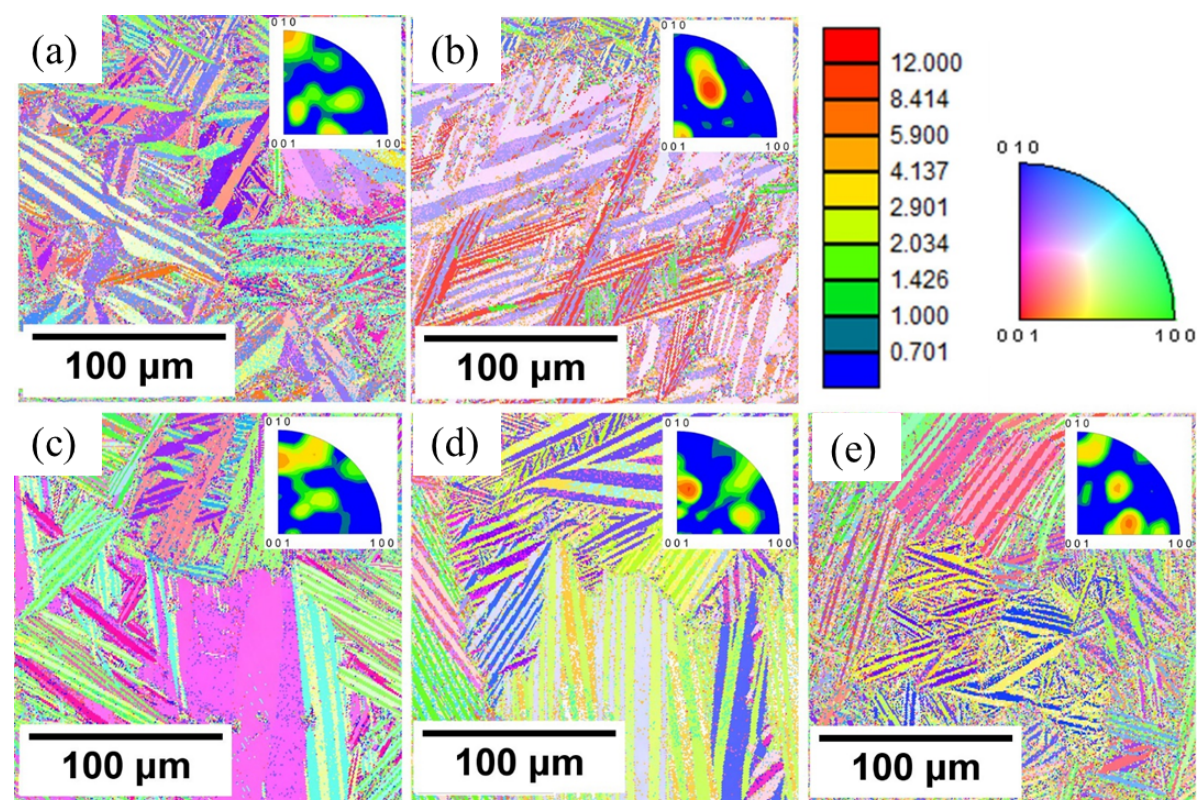

Fig. 7 Inverse pole figures on ND of ingots after $40 \%$ compression at $1000^{\circ} \mathrm{C}$. (a) Ti-50Pd-7Zr, (b) Ti-50Pd-10Zr, (c) Ti-50Pd-4Zr-1V, (d) Ti-50Pd-2.5Zr$2.5 \mathrm{~V}$, and (e) Ti-50Pd-1Zr-4V.
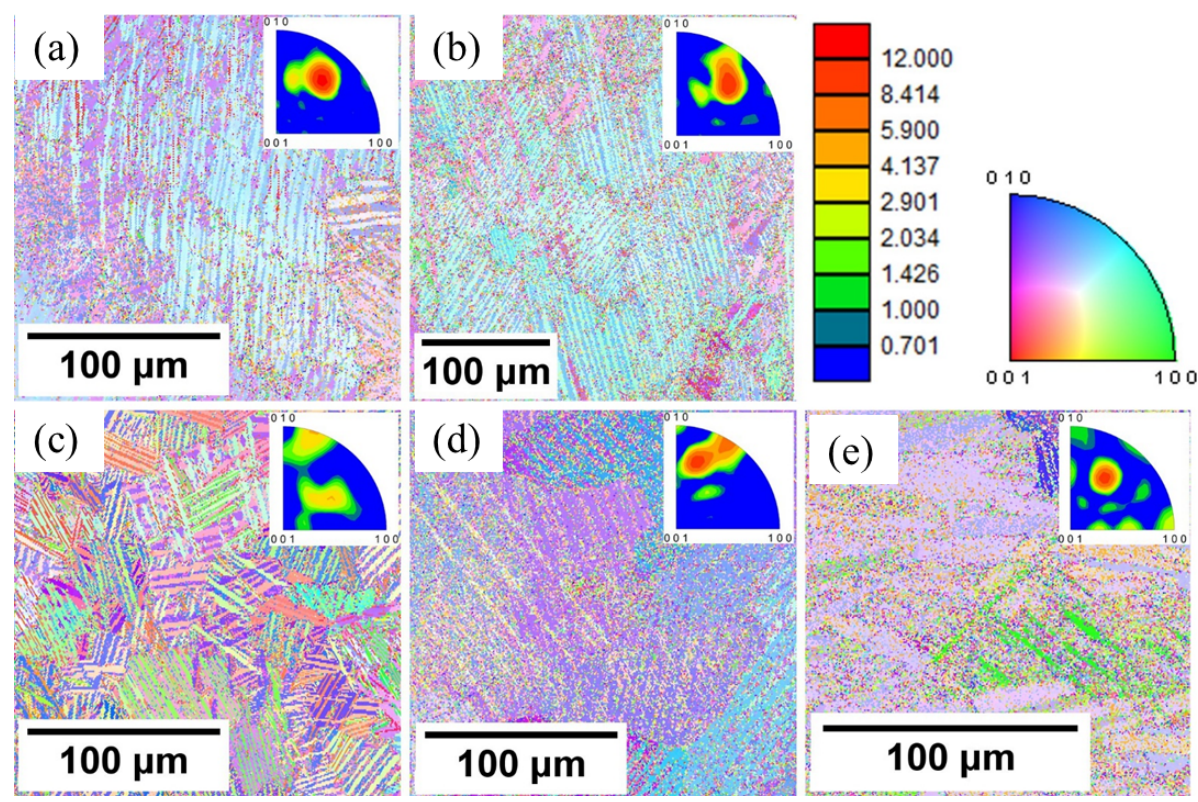

Fig. 8 Inverse pole figures on ND of trained samples. (a) Ti-50Pd-7Zr, (b) Ti-50Pd-10Zr, (c) Ti-50Pd-4Zr-1V, (d) Ti-50Pd-2.5Zr-2.5V, and (e) Ti-50Pd$1 \mathrm{Zr}-4 \mathrm{~V}$.

$1 \mathrm{Zr}-4 \mathrm{~V}$ and Ti-50Pd-2.5Zr-2.5V are almost same in the applied stress range. It indicates that the strengths of the martensite and austenite phase did not affect shape recovery ratio in Ti-50Pd-Zr-V alloys. The higher strength of Ti$50 \mathrm{Pd}-1 \mathrm{Zr}-4 \mathrm{~V}$ has rather the consequential effect to training. The maximum applied stress to achieve perfect recovery of the Ti-50Pd- $1 \mathrm{Zr}-4 \mathrm{~V}$ is $150 \mathrm{MPa}$, higher than Ti-50Pd-4Zr$1 \mathrm{~V}(50 \mathrm{MPa})$ and Ti-50Pd-2.5Zr-2.5V (65 MPa) as shown in Fig. 6 (c-e). Although simple comparison is difficult because the alloys are subjected to thermal cyclic tests under different conditions, the alloys with high austenite strength have trend to show high applied stress to achieve perfect recovery. This is also demonstrated by Ti-50Pd-10Zr. The applied stress to achieve perfect recovery of Ti-50Pd-10Zr
(200 MPa) with higher austenite strength (547 MPa) is higher than that of Ti-50Pd-7Zr (50 MPa) with lower austenite strength (355 MPa).

\subsection{Training effect}

It is suggested that the accumulation of dislocations introduced during training reduces the number of newly introduced dislocations, and eventually, the saturation of the dislocations. For example, in NiTi alloys, the irrecoverable strain disappeared and perfect shape recovery was obtained after 100 cycles under a constant applied stress ${ }^{31}$. The total residual strain that accumulates during training was smaller in alloys strengthened by alloying elements and/or precipitation hardening. In another study, the amount of residual 
strain during the initial thermal cycles of NiTiPd with severe plastic deformation by equal channel angular extrusion (ECAC) significantly reduced, and the number of cycles requiring the stable strain also reduced ${ }^{29)}$. This indicates that the high dislocation density introduced by ECAC effectively stabilizes the accumulation of dislocations and reduces the irrecoverable strain quickly. In our study, the alloys are subjected to thermal cyclic tests under different conditions; hence, the effect of training is not clear. However, accumulation of dislocations is considered to occur during training, which stabilizes the shape recovery behavior in the tested alloys.

Trained alloys, which exhibited perfect recovery, had a specific crystal orientation. It is well known that reorientation of the martensite variant occurs to relieve stress during deformation. The orientation dependence of the transformation strain was calculated using the method reported in Ref. 32).

By using the lattice parameters for the austenite phase with the B2 structure $\left(a_{0}\right)$ and the orthorhombic martensite phase with the B19 structure $\left(a^{\prime}, b^{\prime}, c^{\prime}\right)$, it is possible to calculate the transformation strain due to the lattice distortion produced by martensitic transformation in the single crystal. Since the lattice correspondence between austenite (B2) and martensite (B19) is expressed as follows, the lattice distortion matrix $\boldsymbol{T}^{\prime}$ is written as below in the coordinates of the martensite:

$[100]_{B 19} / /[10 \overline{1}]_{B 2},[010]_{B 19} / /[010]_{B 2},[001]_{B 19} / /[101]_{B 2}$

$$
\boldsymbol{T}^{\prime}=\left[\begin{array}{ccc}
a^{\prime} / \sqrt{2} a_{0} & 0 & 0 \\
0 & b^{\prime} / a_{0} & 0 \\
0 & 0 & c^{\prime} / \sqrt{2} a_{0}
\end{array}\right]
$$

The lattice distortion matrix $\boldsymbol{T}$ with respect to the coordinates of the austenite phase is as follows:

$$
\boldsymbol{T}=\boldsymbol{R} \boldsymbol{T}^{\prime} \boldsymbol{R}^{t},
$$

where $\boldsymbol{R}$ is the matrix for coordinate transformation from martensite to austenite, and $\boldsymbol{R}^{t}$ is the transposed matrix of $\boldsymbol{R}$. From the lattice correspondence between austenite (B2) and martensite (B19), $\mathrm{R}$ is expressed as follows:

$$
\boldsymbol{R}=\left[\begin{array}{ccc}
1 / \sqrt{2} & 0 & 1 / \sqrt{2} \\
0 & 1 & 0 \\
-1 / \sqrt{2} & 0 & 1 / \sqrt{2}
\end{array}\right]
$$

The lattice distortion matrix $\mathrm{T}$ of martensitic transformation can be represented by substituting eqs. (1) and (3) in eq. (2).

$\boldsymbol{T}=\left[\begin{array}{ccc}1 / \sqrt{2} & 0 & 1 / \sqrt{2} \\ 0 & 1 & 0 \\ -1 / \sqrt{2} & 0 & 1 / \sqrt{2}\end{array}\right]\left[\begin{array}{ccc}a^{\prime} / \sqrt{2} a_{0} & 0 & 0 \\ 0 & b^{\prime} / a_{0} & 0 \\ 0 & 0 & c^{\prime} / \sqrt{2} a_{0}\end{array}\right]\left[\begin{array}{ccc}1 / \sqrt{2} & 0 & -1 / \sqrt{2} \\ 0 & 1 & 0 \\ 1 / \sqrt{2} & 0 & 1 / \sqrt{2}\end{array}\right]$

Similarly, the lattice distortion matrix $\mathrm{T}$ of reverse martensitic transformation is represented as follows:

$\boldsymbol{T}=\left[\begin{array}{ccc}1 / \sqrt{2} & 0 & 1 / \sqrt{2} \\ 0 & 1 & 0 \\ -1 / \sqrt{2} & 0 & 1 / \sqrt{2}\end{array}\right]\left[\begin{array}{ccc}\sqrt{2} a_{0} / a^{\prime} & 0 & 0 \\ 0 & a_{0} / b^{\prime} & 0 \\ 0 & 0 & \sqrt{2} a_{0} / c^{\prime}\end{array}\right]\left[\begin{array}{ccc}1 / \sqrt{2} & 0 & -1 / \sqrt{2} \\ 0 & 1 & 0 \\ 1 / \sqrt{2} & 0 & 1 / \sqrt{2}\end{array}\right]$

The transformation strain in each orientation is estimated as follows:

$$
\varepsilon=\frac{\left|x^{\prime}\right|-|x|}{|x|}
$$

where $\boldsymbol{x}^{\prime}=\boldsymbol{T} \boldsymbol{x}$.

To calculate the transformation strain, the lattice parameters of austenite (B2) and martensite (B19) shown in Table 4 were used. The lattice parameters were measured at different temperatures up to above $A_{\mathrm{f}}$ using high-temperature X-ray analysis. Then, the lattice parameters for martensite (B19) were extrapolated to $A_{\mathrm{f}}+30^{\circ} \mathrm{C}$ and compared with those for austenite (B2) at the same temperature.

Figure 9 shows the distribution of the transformation strain of Ti-50Pd-7Zr. Figure 9 represents the transformation strain during martensitic transformation (Fig. 9 (a)) and reverse transformation (Fig. 9(b)) drawn in the austenite (B2) coordinate. Along the [010] direction, the maximum compressive strain was obtained during martensite transformation (Fig. 9(a)) and the maximum expansion strain was obtained during reverse transformation (Fig. 9(b)). This indicates that the maximum recovery strain is obtained when the compression axis is parallel to the [010] direction. The selected direction, as shown in Fig. 8, should be advantageous to obtain a large strain during deformation. However, the textured direction in Fig. 8 is not parallel to the [010] direction. This is because samples are polycrystals and the loading direction is not [010] in the observed grains. In polycrystals, the martensite variant that [010] direction is close to the loading direction must be preferentially selected during deformation. As seen in Fig. 8, the alloy with a strong texture shows perfect recovery, but the alloy with a weak texture, such as Ti-50Pd-4Zr-1V, does not show perfect recovery. Therefore, obtaining a strongly textured structure during training is important to achieve perfect recovery.

Table 4 Lattice parameters for martensite $\left(a^{\prime}, b^{\prime}, c^{\prime}\right)$ and austenite $\left(a_{0}\right)$ used to calculate transformation strain.

\begin{tabular}{lllll}
\hline alloys & $a^{\prime}, \AA$ & $b^{\prime}, \AA$ & $c^{\prime}, \AA$ & $a_{0}, \AA$ \\
\hline Ti-50Pd-7Zr & 4.638 & 2.975 & 4.847 & 3.190 \\
Ti-50Pd-10Zr & 4.571 & 2.781 & 4.942 & 3.272 \\
Ti-50Pd-4Zr-1V & 4.618 & 2.812 & 4.942 & 3.202 \\
Ti-50Pd-2.5Zr-2.5V & 4.644 & 2.770 & 4.839 & 3.195 \\
Ti-50Pd-1Zr-4V & 4.603 & 2.824 & 4.878 & 3.179 \\
\hline
\end{tabular}

(a)
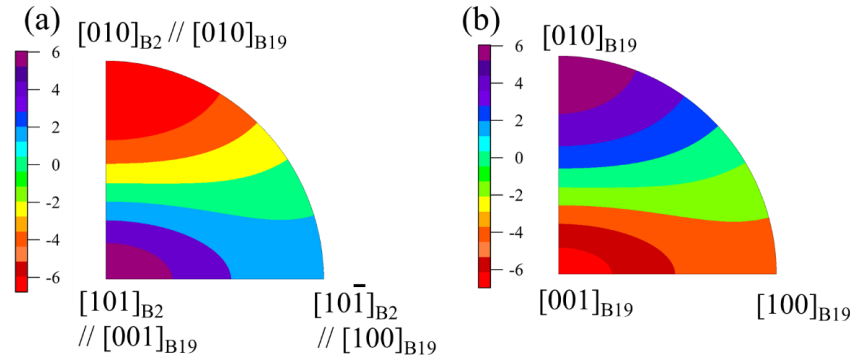

Fig. 9 Orientation dependence of transformation strain in (a) B2 coordinate during martensitic transformation and (b) B19 coordinate during reverse martensitic transformation. 


\section{Conclusion}

The training effect of microstructure and shape recovery on the Ti-50Pd-xZr ( $=7$ and 10) and Ti-50Pd-xZr- $(5-x) \mathrm{V}$ $(\mathrm{x}=1,2.5$, and 4$)$ alloys were investigated.

(1) Martensitic transformation (MT) temperatures decreased with increasing $\mathrm{Zr}$ content. By the addition of 10 at $\% \mathrm{Zr}, M_{\mathrm{f}}$ and $A_{\mathrm{f}}$ was reduced to 302 and $416^{\circ} \mathrm{C}$, respectively. In Ti-50Pd-Zr-V alloys, $A_{\mathrm{s}}$ and $A_{\mathrm{f}}$ increased while $M_{\mathrm{S}}$ and $M_{\mathrm{f}}$ decreased from $4 \mathrm{Zr}-1 \mathrm{~V}$ to $2.5 \mathrm{Zr}-2.5 \mathrm{~V}$. In contrast, from $2.5 \mathrm{Zr}-2.5 \mathrm{~V}$ to $1 \mathrm{Zr}-4 \mathrm{~V}, A_{\mathrm{s}}$ and $A_{\mathrm{f}}$ decreased while $M_{\mathrm{S}}$ and $M_{\mathrm{f}}$ increased. These MT temperatures were between 350 and $550^{\circ} \mathrm{C}$.

(2) Shape recovery was investigated using the thermal cyclic test under a constant applied stress. Perfect recovery was obtained at low stresses, while irrecoverable strain was observed at high stresses. For Ti-50Pd-2.5Zr-2.5V and Ti-50Pd-1Zr-4V, creep deformation was observed above $150 \mathrm{MPa}$. The shape recovery of Ti-50Pd-Zr alloys was above $90 \%$ for up to $150 \mathrm{MPa}$, but decreased significantly with increasing applied stress.

(3) Thermomechanical testing, i.e., training, was performed to obtain perfect recovery. Perfect recovery was obtained for alloys except Ti-50Pd-4Zr-1V. Ti-50Pd-10Zr achieved perfect recovery at $200 \mathrm{MPa}$, and Ti-50Pd-1Zr$4 \mathrm{~V}$ achieved perfect recovery at $150 \mathrm{MPa}$. The other alloys achieved perfect recovery at lower stresses of 65 or $50 \mathrm{MPa}$.

(4) The microstructure of the alloys changed during training. While a random martensite variant was observed before training, textures oriented in a specific direction appeared after training. Strong texture caused perfect recovery, while a weak texture led to irrecoverable strain even after a large number of thermal cyclic tests.

\section{Acknowledgments}

Authors thank the NIMS research fund for supporting this research.

\section{REFERENCES}

1) K. Otsuka and C. M. Wayman: Shape Memory Materials, (Cambridge University Press, Cambridge, 1998) pp.220-280.

2) J. Ma, I. Karaman and R.D. Noebe: Int. Mater. Rev. 55 (2010) $257-$ 315 .

3) G.S. Bigelow, S.A. Padula, II, A. Garg, D. Gaydosh and R.D. Noebe: Metall. Mater. Trans., A 41 (2010) 3065-3079.

4) L. Kovarik, F. Yang, A. Garg, D. Diercks, M. Kaufman, R.D. Noebe and M.J. Mills: Acta Mater. 58 (2010) 4660-4673.
5) K.C. Atli, I. Karaman, R.D. Noebe, A. Garg, Y.I. Chumlyakov and I.V. Kireeva: Metall. Mater. Trans., A 41 (2010) 2485-2497.

6) K.C. Atli, I. Karaman, R.D. Noebe and H.J. Maier: Scr. Mater. 64 (2011) 315-318.

7) K.C. Atli, I. Karaman and R.D. Noebe: Scr. Mater. 65 (2011) 903906.

8) K.C. Atli, I. Karaman, R.D. Noebe, A. Garg, Y.I. Chumlyakov and I.V. Kireeva: Acta Mater. 59 (2011) 4747-4760.

9) Y.Q. Wang, Y.F. Zheng, W. Cai and L.C. Zhao: Scr. Mater. 40 (1999) 1327-1331.

10) X.L. Meng, Y.F. Zheng, Z. Wang and L.C. Zhao: Mater. Lett. 45 (2000) 128-132.

11) X.L. Meng, Y.F. Zheng, Z. Wang and L.C. Zhao: Scr. Mater. 42 (2000) 341-348.

12) B. Kockar, I. Karaman, J.I. Kim and Y. Chumlyakov: Scr. Mater. 54 (2006) 2203-2208.

13) H.Y. Kim, T. Jinguu, T.-H. Nam and S. Miyazaki: Scr. Mater. 65 (2011) 846-849.

14) G.S. Bigelow, A. Garg, S.A. Padula, II, D.J. Gaydosh and R.D. Noebe: Scr. Mater. 64 (2011) 725-728.

15) D.R. Coughlin, P.J. Phillips, G.S. Bigelow, A. Garg, R.D. Noebe and M.J. Mills: Scr. Mater. 67 (2012) 112-115.

16) O. Benafan, R.D. Noebe, S.A. Padula, II and R. Vaidyanathan: Metall. Mater. Trans., A 43 (2012) 4539-4552.

17) A. Evirgen, I. Karaman, R.D. Noebe, R. Santamarta and J. Pons: Scr. Mater. 69 (2013) 354-357.

18) H.E. Karaca, S.M. Saghaian, G. Ged, H. Tobe, B. Basaran, H.J. Maier, R.D. Noebe and Y.I. Chumlyakov: Acta Mater. 61 (2013) 7422-7431.

19) O. Benafan, A. Grag, R.D. Noebe, G.S. Bigelow, S.A. Padula, II, D.J. Gaydosh, N. Schell, J.H. Mabe and R. Vaidyanathan: Intermetallics 50 (2014) 94-107.

20) A. Evirgen, I. Karaman, R. Santamarta, J. Pons and R.D. Noebe: Scr. Mater. 81 (2014) 12-15.

21) A. Evirgen, I. Karaman, R. Santamarta, J. Pons and R.D. Noebe: Acta Mater. 83 (2015) 48-60.

22) K. Otsuka, K. Oda, Y. Ueno, M. Piao, T. Ueki and H. Horikawa: Scr. Metall. Mater. 29 (1993) 1355-1358.

23) D. Golberg, Y. Xu, Y. Murakami, S. Morito and K. Otsuka: Intermetallics 3 (1995) 35-46.

24) S. Shimizu, Y. Xu, E. Okunishi, S. Tanaka, K. Otsuka and K. Mitose: Mater. Lett. 34 (1998) 23-29.

25) P.K. Kumar, U. Desai, J.A. Monroe, D.C. Lagoudas, I. Karaman, G. Bigelow and R.D. Noebe: Mater. Sci. Eng. A 530 (2011) 117-127.

26) Y. Yamabe-Mitarai, R. Arockiakumar, A. Wadood, K.S. Suresh, T. Kitashima, T. Hara, M. Shimojo, W. Tasaki, M. Takahashi, S. Taahashi and H. Hosoda: Material Today Proceedings 2 (2015) S517-S522.

27) R. Arockiakumar, M. Takahashi, S. Takahashi and Y. Yamabe-Mitarai: Mater. Sci. Eng. A 585 (2013) 86-93.

28) M. Kawakita, M. Takahashi, S. Takahashi and Y. Yamabe-Mitarai: Mater. Lett. 89 (2012) 336-338.

29) K.C. Atli, B.E. Franco, I. Karaman, D. Gaydosh and R.D. Noebe: Mater. Sci. Eng. A 574 (2013) 9-16.

30) Y. Yamabe-Mitarai: Mater. Sci. Forum 879 (2016) 107-112.

31) K.C. Atli, I. Karaman, R.D. Noebe and D. Gaydosh: Mater. Sci. Eng. A 560 (2013) 653-666.

32) H.Y. Kim, T. Sasaki, K. Okusu, J.I. Kim, T. Inamura, H. Hosoda and S. Miyazaki: Acta Mater. 54 (2006) 423-433. 